American Journal of Pharmaceutical Education 2019; 83 (6) Article 6848.

\title{
RESEARCH
}

\section{Pharmacy Students' Perspectives on Interprofessional Learning in a Simulated Patient Care Ward Environment}

\author{
Louise E. Curley, PhD, ${ }^{\mathrm{a}}$ Maree Jensen, ${ }^{\mathrm{a}}$ Carolyn McNabb, PhD, ${ }^{\mathrm{a}}$ Sanya Ram, LLB, ${ }^{\mathrm{a}}$ \\ Jane Torrie, $\mathrm{MBChB},{ }^{\mathrm{b}}$ Tanisha Jowsey, $\mathrm{PhD},{ }^{\mathrm{c}}$ Maureen McDonald ${ }^{\mathrm{a}}$ \\ a School of Pharmacy, Faculty of Medical and Health Sciences, The University of Auckland, Auckland, New Zealand \\ ${ }^{\mathrm{b}}$ Department of Anaesthesiology, Faculty of Medical and Health Sciences, The University of Auckland, Auckland, \\ New Zealand \\ ${ }^{c}$ Centre for Medical and Health Sciences Education, Faculty of Medical and Health Sciences, The University of \\ Auckland, Auckland, New Zealand \\ Submitted October 13, 2017; accepted February 15, 2018; published August 2019.
}

\begin{abstract}
Objective. To assess pharmacy students' opinions of an interprofessional learning (IPL) course in their final year of the Bachelor of Pharmacy program at The University of Auckland.

Methods. Pharmacy students participated in the second day of a two-day simulation-based course, WardSim, alongside medical and nursing students in an acute care, hospital ward setting. After finishing the course, all students were asked to complete a questionnaire. The responses of pharmacy, nursing, and medical students on the scaled questions were compared. An in-depth thematic analysis of the pharmacy students' responses to the open-ended questions was completed using an iterative process. Results. Significant differences were found among the students' responses regarding the prioritization of care, systematic assessment of patients, and communication strategies. Pharmacy students had less favourable responses regarding the IPL experience than medical and nursing students. However, overall responses were positive. Some of the themes that emerged among the pharmacy students' responses included: learning communication tools, being assertive in communicating with other health care professionals, and understanding their own and others' roles in the health care team. Furthermore, some pharmacy students reported feeling underprepared for and underutilized during patient care scenarios. Conclusion. An IPL experience in an acute patient care setting demonstrated clear and beneficial learning outcomes for pharmacy students, especially in regards to communicating and understanding their roles and those of others on their team. Tailoring the pre-work or scenarios for the IPL experience to be more pharmacy orientated and having pharmacy students participate on both days may improve the preparedness for IPL.
\end{abstract}

Keywords: interprofessional education, pharmacy students, simulation

\section{INTRODUCTION}

Effective communication between health care professionals is vital as poor communication has consistently been associated with adverse patient safety events. ${ }^{1,2}$ For example, a significant number of events have been linked to the transition of patient care between health care professional services, both within teams and between disciplines. ${ }^{3,4}$ Having effective communication strategies between health care professionals is therefore vital, $2,5-8$

Corresponding Author: Louise E. Curley, School of Pharmacy, Faculty of Medical and Health Sciences, The University of Auckland, Private Bag 92019, Auckland 1142, New Zealand. Tel: +64-9-9232255. Fax: +64-9-3677192.

E-mail: 1.curley@auckland.ac.nz as is each health care professional understanding his or her own role in the team in order to facilitate optimum patient care. Therefore, health care professionals being able to effectively collaborate and work in teams is essential.

To better prepare health care students for the workforce, experiential learning, development of core skills, and interprofessional learning (IPL) are all vital components of health care curricula. ${ }^{9}$ Interprofessional learning activities are occasions where students of two or more professions learn with, from, and about one another to improve collaboration and the quality of care. ${ }^{10,11}$ Interprofessional learning has been recognized by the Accreditation Council for Pharmacy Education (ACPE) as a key element in the development of pharmacy education programs. ${ }^{9}$ Standard 11.2 of ACPE's "Standards 2016" 


\section{American Journal of Pharmaceutical Education 2019; 83 (6) Article 6848.}

emphasizes interprofessional education "to advance collaboration and quality of patient care, the didactic and experiential curricula include opportunities for students to learn about, from, and with other members of the interprofessional health care team." ${ }^{\text {9 }}$ In addition, Standard 12 encourages the development of pharmacy curricula with an emphasis on provision of patient-centered care within an interprofessional health care team. ${ }^{9}$ The Center for the Advancement of Pharmacy Education (CAPE) also recognizes the importance of IPL, stating that an essential premise of the CAPE educational outcomes is for a pharmacist to be able to function in a collaborative environment within an interprofessional team. ${ }^{11}$ At a broader health care level, the World Health Organization (WHO) launched a study group on Interprofessional Learning and Collaborative Practice to assess the current international research in this field. ${ }^{12}$ They concluded that there was "sufficient evidence to indicate that interprofessional education enables effective collaborative practice" and that "collaborative practice strengthens health, and improves health outcomes." 12

Studies have suggested that IPL is most effective when students learn together rather than in parallel. ${ }^{13,14}$ However, research on IPL involving students from multiple health care disciplines is somewhat limited. ${ }^{15-22}$ Student responses from studies indicate that IPL is valuable, relevant, and enjoyable. ${ }^{15,18,23,24}$ IPL experiences increase students' confidence and provide more clarity about their own and other professionals' roles and identity as part of the health care team. ${ }^{24-27}$ In addition, self-efficacy beliefs regarding interprofessional and interpersonal communication are positively affected by IPL. ${ }^{15,28}$ There has been an increase in IPL research over the past decade. ${ }^{29}$ While some studies have investigated how pharmacy students perceive IPL, 3,19-22,24,28,30-32 few have specifically evaluated how IPL affects their perception of interprofessional communication and teamwork as well as clarity regarding their roles and those of others.

At The University of Auckland in New Zealand, pharmacy students learn alongside medical and nursing students at three major points within the curriculum: Maori Health Intensive, a four-day team-based learning program led by indigenous Māori health researchers and teachers that focuses on Māori health and socio-political and economic determinants of health inequities; ${ }^{33,34}$ Quality and Safety, a two-day teaching workshop; ${ }^{34}$ and WardSim, which was added in 2014, a two-day interprofessional simulation-based course for final year nursing and year 5 medical students (enrolled in a six-year program), with final year pharmacy students joining them on day $2 .{ }^{35}$ WardSim has specific IPL objectives in the con- text of interprofessional management of acute new problems that inpatients develop. The stated objectives of WardSim are to increase role clarity, define scope of practice for each profession, and learn structured communication tools. Research regarding this IPL course is multi-layered and has included student feedback obtained from the Readiness for Interprofessional Learning Scale, ${ }^{36}$ end of course evaluations, and a questionnaire that included Likert-type scale items as well as openended items. The research in this study focused on feedback from the questionnaire.

The purpose of this study was to provide an overview of the WardSim IPL course that was developed at The University of Auckland, NZ, and to determine pharmacy students' outcomes from the experience compared to the outcomes for the other health professions groups. We specifically looked at pharmacy students' perceptions regarding their role and roles of others, interprofessional team dynamics, communication, patient assessment, and patient safety.

\section{METHODS}

In 2014, this two-day course incorporated four simulated scenarios and debriefs each day, interspersed with classroom activities on related topics. Students were assigned to mixed professional groups of between eight and 11 members and worked in these groups for the duration of the course. Pharmacy students did not join the other students until the second day and therefore only took part in the four classroom activities of prioritization of ward tasks, speaking up, medicines reconciliation, and correcting medicines charting errors.

All students received a link to electronic resources on the communication tool ISBAR ${ }^{37}$ prior to the course, and on day 1, medical and nursing students took part in a classroom activity on this topic. On day 2, the speaking up activity followed a structured framework that included use of a pneumonic for managing concerns (PACER (probe, alert, challenge, emergency, react). ${ }^{37}$

The scenarios provided the opportunity for students to use these communication tools in ward-based situations. Each pharmacy student was directly involved in at least one scenario. Medical and pharmacy students were asked to take on the role of a trainee intern (for information regarding medical trainee intern see Tweed and colleagues ${ }^{38}$ ), while nursing students were asked to act as new graduate nurses.

The scenarios presented undifferentiated problems arising in inpatients that required assessment and management of the patient but not resuscitation. The duration of the scenario was 30 minutes: nursing and pharmacy students entered each scenario 15 minutes before medical 


\section{American Journal of Pharmaceutical Education 2019; 83 (6) Article 6848.}

students. The scenarios on day 2 involved four cases: a patient with increasing abdominal pain and respiratory difficulty post trauma surgery (the pharmacy students only observed in this scenario), a patient with iatrogenic anticoagulant overdose with minor bleeding, a surgical patient with neurological symptoms who was taking lithium, and an epileptic patient who had experienced a brief seizure. The debriefing for each case lasted 30 minutes. Facilitators ensured that the students who had only observed as well as the "hands on" participants were involved in the discussions.

Interprofessional faculty members from each of the programs (medical, nursing, and pharmacy) facilitated WardSim. Each facilitator undertook a half-day training session and attended a faculty debriefing at the end of each day. The typical ratio of faculty members to students was 1:5 and of simulation technical staff members to students was 1:20.

At the end of day 2, verbal comments regarding WardSim were elicited from students in a final 30-minute session. Students were specifically asked to comment on personal learning and what the presence of students from other professions contributed to the course. During this time, a facilitator guided students' verbal reflections on the course. After this reflection time, all students were asked to complete a voluntary written questionnaire that included 10 statements rated on a Likert-type scale of 1 to $5(1=$ strongly disagree and $5=$ strongly agree $)$, and associated open-ended questions with free text fields. Questions concerned participant challenges, prioritization, communication strategies, roles of self, roles of others, patient safety strategies, systematic assessments, and sharing information between team members (Tables 1 and 2).

Quantitative responses were recorded in Microsoft Excel 2010 and transferred to SPSS Statistics version 22.0 (IBM, Armonk, NY). The non-parametric Kruskal-Wallis test ${ }^{39}$ was used to test for differences in responses among the three groups (medicine, nursing, pharmacy) for each question, corrected for multiple comparisons using the false discovery rate (FDR). Post-hoc pairwise comparisons determined the nature of any differences found. Free text responses were recorded in Excel, and key emergent themes were established following iterative thematic coding to a coding scheme. Responses were read individually by two members of the research team before being coded separately. A third member then viewed the two separate codings to compare them, with additional codes suggested when necessary. The codes that emerged were used to identify broad themes in response to the overall aims of the study. The authors checked and agreed that the themes accurately represented the student responses. Results were compared with and without nonresponder data to the Likert-type scale data to ensure that the interpolation did not affect the results. Ethics approval for the study was granted by The University of Auckland Human Participants Ethics Committee as part of a larger study.

\section{RESULTS}

Ninety-seven Bachelor of Pharmacy (BPharm) students were among the 388 students who participated in six WardSim cycles between April and September 2014. All participants were invited to complete the questionnaire. Sixteen of the students who completed the questionnaire did not indicate to which professional group they belonged, so their responses were therefore excluded from the analysis. Eighty-one respondents $(83.5 \%)$ were pharmacy students, 154 (77.9\%) were medical students, and $69(75.0 \%)$ were nursing students.

Seventeen students, including seven from pharmacy, seven from nursing, and three from medicine, did not complete all items on the questionnaire. In total, 29 items from the 17 questionnaires had missing data. Analyses were run including and excluding the data from the 17 participants. Because no differences were found in the number of significant results, the data were included for completeness.

Overall, the majority of students agreed or strongly agreed with all statements. Students' responses were particularly positive about learning with other professional

Table 1. Description of Likert-type Questions From the Questionnaire

\section{Likert-type Question}

1. The course helped me to prioritise competing requests for patient care

2. I learnt strategies to help me communicate more effectively.

3. I feel clearer about my role in a patient care team.

4. I feel clearer about the roles and capabilities of others from different disciplines in the patient care team.

5. I learnt strategies to improve the safety of prescribing medications.

6. I learnt to be more systematic in patient assessment.

7. I learnt more on this course by sharing it with other professional groups.

8. Having other professional groups on the course challenged the way I thought about them. 


\section{American Journal of Pharmaceutical Education 2019; 83 (6) Article 6848.}

Table 2. Description of the Free Text Questions, Associated with the Likert-type Questions

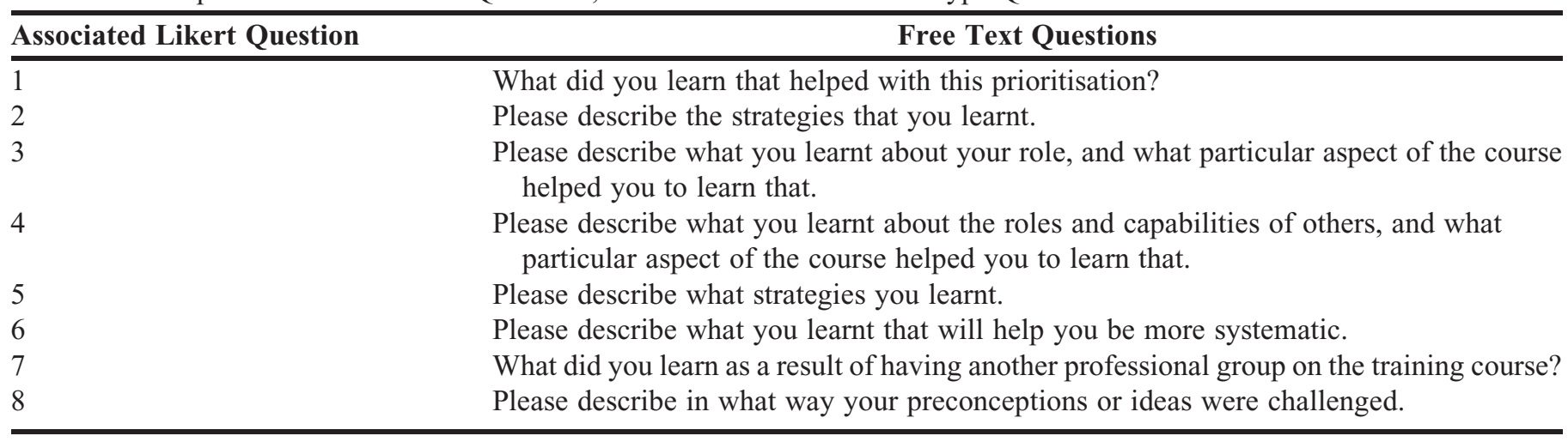

groups, increased understanding of others' roles, and communication strategies learned. They were less positive about learning systematic patient assessment and safe prescribing strategies, and felt that their ideas about other professions had been challenged by the course. Pharmacy students were less positive about the experience overall compared with nursing and medicine students. Table 3 presents responses to the Likert scale statements for all three groups of students.
The Kruskal-Wallis non-parametric test was used to assess differences among the three groups. Significance was taken at the FDR-adjusted $p \leq .018$; an adjusted value was used to account for multiple comparisons. Significant differences were seen between the groups in response to three of the items: questions 1, 2, and 7. Pairwise comparisons showed where the differences originated (Table 4). On all three questions, pharmacy students responded differently than medical students did. On question 7 ,

Table 3. Percentage of Responses to each Likert-type Question Evaluating the IPL in a Simulated Patient Care Environment Across all Student Groups: Medicine, Nursing and Pharmacy

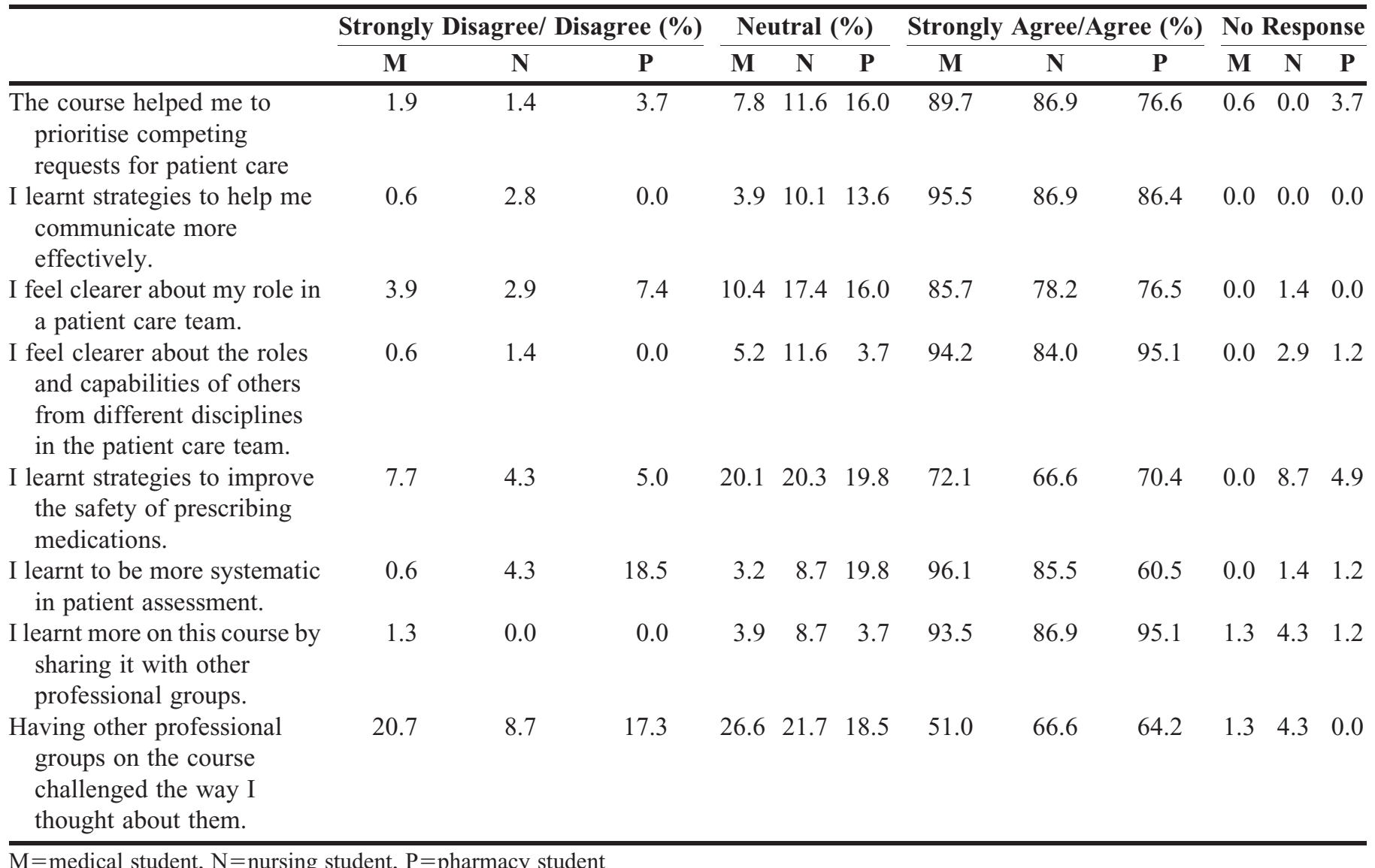




\section{American Journal of Pharmaceutical Education 2019; 83 (6) Article 6848.}

pharmacy students' responses were also significantly different from those of nursing students.

In regards to the open-ended questions, six key themes were identified from the pharmacy students' responses, as outlined in Table 5, and examples are provided by theme and subtheme in Appendix 1. These themes and subthemes are described below.

The first theme to emerge was "roles and teamwork." Many of the students described WardSim as clarifying their understanding of their own role and the roles of other health care professionals on the team. Students reported that WardSim increased their knowledge of how to function effectively within a team and also increased their clarity about the strengths and limitations of their own roles in terms of team dynamics. A number of students indicated that prior to taking the course, they had limited knowledge of where and how they were expected to function within interprofessional teams, and that WardSim offered them clarity and experiential learning, and subsequently they valued understanding their own strengths and limitations. Some pharmacy students reported confusion or frustration about what their roles were in the team environment. Following WardSim they remained unclear about the value they could offer to the team, what they should do to help during an acute patient incident, and where their voice had a place within the power dynamics at play within the environment. These students reported that they felt their only contribution to effective management in any of the patient scenarios was to check medications. Many students remarked that WardSim expanded their thoughts about how the teams could function effectively and the importance of each member of the team.
Different opinions within the teams were valued by students and broadened their awareness of different perspectives of approaching scenarios. Students also highlighted that working collaboratively included asking for help from others within the team when required.

The second theme to emerge was "communication: assertiveness and confidence in team environments." Development and practice of interpersonal communication in the interprofessional team environment was another theme that emerged from the free-text questions in this study. Participants reported that WardSim had enhanced students' abilities to be respectfully assertive and have the confidence to find their own voice within the team dynamic.

Knowledge was another theme. Statements regarding students' own knowledge and the knowledge of students from other disciplines were made. Subthemes of preparedness and under-preparedness emerged in students' answers, in addition to the value of sharing knowledge between students. Some students felt that they were underprepared for the simulations, and compared their performance in the course to that of students from other disciplines.

The fourth emergent theme was communication strategies. Tools were a key theme in the majority of students' answers. Sixty-nine (85\%) students commented on general tools or specific tools when asked to describe strategies that they learned during the course, including PACER and CUSS (concern, unsure, safety, stop), while others eluded to communication tools learned such as the shared mental model and recapping.

Table 4. Pairwise Comparison of the Responses to the Likert-type Questions Evaluating the IPL in a Simulated Patient Care Environment by Student Groups ${ }^{\mathrm{a}}$

\begin{tabular}{|c|c|c|c|}
\hline Comparison & Test Statistic & Standard Error & Significance \\
\hline \multicolumn{4}{|c|}{ Question 1: The course helped me to prioritize competing requests for patient care } \\
\hline Pharmacy-Nursing & -15.275 & 12.977 & .72 \\
\hline Pharmacy-Medicine & -34.728 & 10.924 & $.004^{\mathrm{b}}$ \\
\hline Nursing-Medicine & -19.453 & 11.386 & .26 \\
\hline \multicolumn{4}{|c|}{ Question 2: I learnt strategies to help me communicate more effectively. } \\
\hline Pharmacy-Nursing & -12.675 & 12.695 & .95 \\
\hline Pharmacy-Medicine & -33.217 & 10.636 & $.005^{\mathrm{b}}$ \\
\hline Nursing- Medicine & -0.542 & 11.226 & .20 \\
\hline \multicolumn{4}{|c|}{ Question 7: I learnt to be more systematic in patient assessment. } \\
\hline Pharmacy-Nursing & -48.228 & 13.158 & $.001^{\mathrm{b}}$ \\
\hline Pharmacy-Medicine & -79.367 & 10.994 & $.000^{\mathrm{b}}$ \\
\hline Nursing- Medicine & -31.139 & 11.615 & .022 \\
\hline
\end{tabular}

${ }^{a}$ Pairwise comparisons of the significant results from the Kruskal-Wallis test. These were only conducted if the Kruskal-Wallis test for that question resulted in a significant result. This will determine where the significance lies within the comparison

${ }^{\mathrm{b}}$ Indicates significance taken at FDR-adjusted $p \leq .018$ to equate for multiple comparisons; all $p$-values expressed to 2 significant figures 


\section{American Journal of Pharmaceutical Education 2019; 83 (6) Article 6848.}

Table 5. Themes and Subthemes Emerged from the Free Text Comments Regarding the IPL in a Simulated Patient Care Environment

\begin{tabular}{ll}
\hline Theme & \multicolumn{1}{c}{ Emerged Subtheme } \\
\hline Roles and teamwork & $\begin{array}{c}\text { Clarity of own role and other health care professionals' roles }- \text { strengths } \\
\text { and limitations } \\
\text { Effective team work } \\
\text { Development and practice of interprofessional communication } \\
\text { Respectful assertion }\end{array}$ \\
& $\begin{array}{l}\text { Confidence } \\
\text { Knowledge }\end{array}$ \\
& $\begin{array}{l}\text { Preparedness/under-prepared } \\
\text { Own and others' knowledge }\end{array}$ \\
& Value of knowledge sharing \\
Communication strategies & Tools - explicit \\
& Tools - described \\
Broader management skills & Logistical time management and resources \\
& Triage, urgency and consequence of care \\
Simulation and opportunity to practice & Patient's perspective \\
& Opportunity to practice \\
& Practice demonstrates roles \\
& Being systematic and procedure examples
\end{tabular}

"Broader management skills" was another theme to emerge. Many students reported that specific attributes of management became apparent with WardSim. Logistical time management and availability of resources was a strong subtheme. Students reported that they had learned about logistical time management and availability of resources, which needed to be taken into consideration. For example, the distance and resources available to them to manage the situations, which had not become apparent prior to WardSim. Triage, urgency of care, and the consequences of prioritization also were noted by many students. Students described triage assessment, assessing the urgency of situations, and understanding potential consequences of care as helping with prioritization. Students reported that within prioritization, seeing scenarios from the patient's perspective and taking this into account should be at the forefront of decisions made within the team.

"Simulation and practice" was the final emergent theme. Students reported the benefits of WardSim as an opportunity to practice, and through this, roles could be established. The respondents detailed that the practice allowed them to become more systematic and aware of procedures.

\section{DISCUSSION}

The results of this study demonstrate that, overall, the WardSim course was perceived by pharmacy students to be a positive experience. However, there were three statements to which pharmacy students responded differently than other groups. Pharmacy students rated the statement, "The course helped me to prioritise competing requests for patient care," less positively than medical students did, and the statement, "I learnt to be more systematic in patient assessment," less positively than both medical and nursing students did. These objectives surrounding prioritizing patient care and assessment were specifically designed with nursing and medical students in mind. Not surprisingly, this statement was rated less favourably by pharmacy students. Interestingly, however, in open-ended responses (discussed in more detail below), pharmacy students commented that the course enabled them to consider the prioritization and triage of patients in care. While this objective was not aimed directly at pharmacy students, there is an emerging role for the pharmacist in these areas in acute patient care settings ${ }^{40}$ and in triage in community settings. ${ }^{41}$ In moving forward with IPL curricula, cases that aim to also target pharmacy students should be considered.

Significant differences were also seen between pharmacy students' responses to "I learnt strategies to help me communicate more effectively" and those of medical students. This was the first time that pharmacy students had been exposed to systematic tools for assertive communication, speaking to another health professional and exchange of information effectively (for example, ISBAR), and we believe that this was reflected in their responses to this question.

We gathered additional information on pharmacy students' perceptions in the free-text responses. Strong themes emerged from the pharmacy students regarding WardSim being an opportunity to understand and provide 


\section{American Journal of Pharmaceutical Education 2019; 83 (6) Article 6848.}

clarity around their own roles and the roles of other health care professionals in an acute setting. Students expressed that through WardSim they had a greater understanding of their own strengths and limitations, as well as those of other health care professionals. The responses also indicated that the course expanded their knowledge of how to function effectively within the team environment; the students indicated that each health care professional needed to contribute in their own way to enhance patient care. These results are in line with previous research by Hagemeier and colleagues who used a survey based on the Interprofessional Education Collaborative Core Competencies to evaluate an interprofessional communications course and reported that pharmacy students noted significant improvements in self-efficacy beliefs in contributing to the health care team and in their understanding of health care roles in the team. ${ }^{28}$ Furthermore, Kostoff and colleagues found that pharmacy students' self-perception of interprofessional competence improved after completing a interprofessional simulation using ISBAR. ${ }^{3}$ The current study highlighted that although many students saw the IPL course as an opportunity to clarify roles, some students felt frustration and confusion over what their place was within the health care team, especially in reference to the role of pharmacists in acute care scenarios. This information is key to future development of IPL activities for pharmacy students. Ensuring that students feel prepared for their role in the types of scenarios with which they will be presented in practice is important.

The importance of establishing a shared mental model also was apparent in student responses. The shared mental model has been described as a way of ensuring that all the resources of the team can be fully utilized. ${ }^{2,42}$ These models also allow for team members to have an understanding of who is responsible for each task so the team may function more effectively. ${ }^{42}$ However, there were mixed reports from students regarding the knowledge that they contributed to the health care team. While some reported that they could see how their knowledge could be integrated into the overall health of the patient, others felt disadvantaged and underprepared in comparison to the other students. This finding was of particular interest to us as students in The University of Auckland's BPharm degree have repeated opportunities to simulate community-based and hospital-based pharmacy practice in their practical sessions, their case management workshops, and on experiential placement. However, the WardSim course is the first time in which they have the opportunity to practice managing acute, ward-based patient cases. Because students may encounter acutely ill patients in their future careers, this course should be considered as vital to arming them with experiential knowl- edge for managing such a situation effectively to ensure the best outcome for the patient. Students from the medical and nursing degree programs spent two days in this IPL simulation compared to the pharmacy students spending one day. The findings of this study suggest that pharmacy students gain a lot from participating in the course. Therefore, we believe that increasing their participation to two days would have multiple benefits for students in terms of IPL, experiential learning, and orienting them for successful engagement with the whole course.

While previous research has reported positive outcomes in communication between health professions ${ }^{3,43}$ and confidence of students undertaking IPL, ${ }^{20,31}$ our study added further understanding to the current literature. In this study, we reported that WardSim helped with the development of more specific interprofessional communication skills, respectful assertiveness, and confidence among pharmacy students. Students also described that the course helped them with finding their voices within the health care professional team.

The current study highlighted the importance of tools as a strategy to improve students' abilities to manage interprofessional situations, which they felt directly had consequences for the safety of prescribing medications. Eighty-five percent of students specifically named the ISBAR, PACER, and/or CUSS tools as strategies that they had learned during WardSim. Other students described recapping and shared mental model techniques. The study by Kostoff and colleagues, ${ }^{3}$ and two studies by Shrader and colleagues ${ }^{30,44}$ have also used the SBAR tool within their IPL designs. The SBAR is a similar structured tool to ISBAR but does not include the "introduction" to begin the communication. These studies both reported improvements in student communication and one reported organizing thoughts prior to communicating with other health care professionals. ${ }^{44}$ Using structured tools such as ISBAR has improved the quality of handover information and has led to a subsequent reduction in incidents. $^{5}$

This study has added to the literature surrounding the use of tools in student-based IPL, ie, 85\% of pharmacy students specifically named the PACER and CUSS tools as strategies learned to improve patient safety. The PACER and CUSS are graded assertiveness tools. Weller and colleagues propose a seven-step plan to overcome barriers to effective communication. The authors describe the need to create a democratic team environment to ensure that everyone within the team can be heard. ${ }^{5}$ One way of creating such an environment is to use a graded assertion tool. Graded assertion is a method to ensure escalating force of information transfer, especially in a 


\section{American Journal of Pharmaceutical Education 2019; 83 (6) Article 6848.}

hierarchical environment. ${ }^{5}$ In addition, many of the students in the WardSim course said this learning gave them a voice on the team and allowed them to assert their opinion. As previous studies have reported that lack of assertiveness and confidence is a barrier to pharmacist integration into the multidisciplinary team,${ }^{45}$ finding that students felt the IPL course provided them with the structured tools they needed to be assertive was interesting and important. We believe this finding is of utmost importance and now are considering introducing these tools at an earlier time in the pharmacy curriculum to allow students to practice using them within the practical aspects of their undergraduate degree and be better prepared for this IPL course.

WardSim also gave students an insight into broader management skills surrounding prioritization in addition to the urgency of condition and the consequences that decisions had on care. Many students stated that the course helped them consider logistical factors, such as time between wards and resources when they were prioritizing competing requests for care. To our knowledge, this has not been reported about any other IPL study involving pharmacy students, and we are discussing ways in which to incorporate this into the curriculum prior to the WardSim course.

Interprofessional learning through simulation has been shown to be effective in medical, nursing, and pharmacy students. ${ }^{13,14}$ Our study adds to this literature, with pharmacy students indicating that WardSim gave them the opportunity to practice skills and observe the roles of health care professionals from other disciplines. This study also highlighted there are areas in which we can improve the learning experience for pharmacy students. In particular in the preparation of pharmacy students for the role of the pharmacist in the acute-care setting and also by introducing the teaching of systematic tools for interprofessional communication. Future research should be conducted to evaluate any changes in outcomes following curricular changes. WardSim has since been developed into a four-day program now called Urgent and Immediate Patient Care Week. In addition, conducting interviews or focus groups with the students could provide a deeper understanding of the discussed topics, including exploring the emotions of students. While this research has provided valuable insight into the perspectives of pharmacy students after an acute ward IPL experience, it did not directly measure whether the course affected students' understanding of how they applied their knowledge in these situations. This is an avenue for future research. The World Health Organization has stated that collaborative practice "strengthens health systems and improves health outcomes." 12 Further research would be useful to analyse how the skills taught within undergraduate curricula translate to the practice of pharmacy, both in the hospital and the community setting.

\section{CONCLUSION}

WardSim is a positive IPL experience for undergraduate pharmacy students, increasing their awareness of their own role in patient care and that of others, and preparing them for future collaborative teamwork environments. In addition, the course gave students the opportunity to become familiar with and practice core interprofessional communication skills and to develop the ability to provide information in a structured and effective manner. Subsequently, pharmacy students reported increased confidence in their ability to verbalize their opinions within a dynamic team environment. However, some students did report feeling frustrated and underprepared for the simulation component of the course. Ensuring that these feelings are addressed and that students are adequately orientated to the type of scenarios that they are going to face is important. While students in the undergraduate BPharm program have several opportunities to practice in a community setting and encounter hospital-based patient cases both in facilitated workshops and on experiential learning placements, this IPL experience has highlighted the need to provide more acute care practice experiences in a ward environment for students.

\section{REFERENCES}

1. The Joint Commission. Sentinel Event Data Root Causes by Event Type 2004-2014. http://www.tsigconsulting.com/tolcam/wp-content/ uploads/2015/04/TJC-Sentinel-Event-Root_Causes_by_Event_Type_20042014.pdf.

2. Brindley PG, Reynolds SF. Improving verbal communication in critical care medicine. J Crit Care. 2011;26(2):155-159.

3. Kostoff M, Burkhardt C, Winter A, Shrader S. An

interprofessional simulation using the SBAR communication tool. Am J Pharm Educ. 2016;80(9):Article 157.

4. Sutcliffe KM, Lewton E, Rosenthal MM. Communication failures: an insidious contributor to medical mishaps. Acad Med. 2004;79(2):186-194.

5. Weller J, Boyd M, Cumin D. Teams, tribes and patient safety: overcoming barriers to effective teamwork in healthcare. Postgrad Med J. 2014;90(1061):149-154.

6. Boaro N, Fancott C, Baker R, Velji K, Andreoli A. Using SBAR to improve communication in interprofessional rehabilitation teams. $J$ Interprof Care. 2010;24(1):111-114.

7. Pugel AE, Simianu VV, Flum DR, Patchen Dellinger E. Use of the surgical safety checklist to improve communication and reduce complications. J Infect Public Health. 2015;8(3):219-225.

8. Boyd M, Cumin D, Lombard B, Torrie J, Civil N, Weller J. Readback improves information transfer in simulated clinical crises. $B M J$ Qual Saf. 2014;23(12):989-993.

9. Accreditation Council for Pharmacy Education. Accreditation standards and key elements for the professional program in pharmacy leading to the doctor of pharmacy degree ("Standards 2016"). https:// 


\section{American Journal of Pharmaceutical Education 2019; 83 (6) Article 6848.}

www.acpe-accredit.org/pdf/Standards2016FINAL.pdf. Published 2016. Accessed August 1, 2019.

10. Parsell G, Bligh J. Interprofessional learning. Postgrad Med J. 1998;74(868):89-95.

11. American Association of Colleges of Pharmacy. Center for the Advancement of Pharmacy Education (CAPE) 2013 Educational Outcomes. https:/www.ncbi.nlm.nih.gov/pmc/articles/PMC3806946/ pdf/ajpe 778162.pdf. Published 2013. Accessed August 1, 2019. 12. World Health Organization: Health Professions Network Nursing and Midwifery Office within the Department of Human Resources for Health. Framework for Action on Interprofessional Education \& Collaborative Practice. http://apps.who.int/iris/ bitstream/10665/70185/1/WHO_HRH_HPN_10.3_eng.pdf?ua=1. Published 2010. Accessed December 21, 2017.

13. Freeth D, Reeves S. Learning to work together: using the presage, process, product (3P) model to highlight decisions and possibilities. J Interprof Care. 2004;18(1):43-56.

14. Hammick M, Freeth D, Koppel I, Reeves S, Barr H. A best evidence systematic review of interprofessional education: BEME Guide no. 9. Med Teach. 2007;29(8):735-751.

15. Bolesta S, Chmil JV. Interprofessional education among student health professionals using human patient simulation. Am J Pharm Educ. 2014;78(5):94.

16. Marken PA, Zimmerman C, Kennedy C, Schremmer R, Smith KV. Human simulators and standardized patients to teach difficult conversations to interprofessional health care teams. Am J Pharm Educ. 2010;74(7):Article 120.

17. Fernandez R, Parker D, Kalus JS, Miller D, Compton S. Using a human patient simulation mannequin to teach interdisciplinary team skills to pharmacy students. Am J Pharm Educ. 2007;71(3):Article 51. 18. MacDonnell CP, Rege SV, Misto K, Dollase R, George P. An introductory interprofessional exercise for healthcare students. $\mathrm{Am} \mathrm{J}$ Pharm Educ. 2012;76(8):Article 154.

19. Saini B, Shah S, Kearey P, Bosnic-Anticevich S, Grootjans J, Armour C. An interprofessional learning module on asthma health promotion. Am J Pharm Educ. 2011;75(2):Article 30.

20. Taylor D, Yuen S, Hunt L, Emond A. An interprofessional pediatric prescribing workshop. [Erratum appears in Am J Pharm Educ. 2013 Dec 16;77(10):230]. Am J Pharm Educ 2012;76(6):Article 111. 21. Wamsley M, Staves J, Kroon L, et al. The impact of an interprofessional standardized patient exercise on attitudes toward working in interprofessional teams. $J$ Interprof Care 2012;26(1):2835 .

22. Westberg SM, Adams J, Thiede K, Stratton TP, Bumgardner MA. An interprofessional activity using standardized patients. Am J Pharm Educ. 2006;70(2):Article 34.

23. MacDonnell C, George P, Nimmagadda J, Brown S, Gremel K. A team-based practicum bringing together students across educational institutions and health professions. Am J Pharm Educ. 2016;80(3):Article 49.

24. Rodehorst TK, Wilhelm SL, Jensen L. Use of interdisciplinary simulation to understand perceptions of team members' roles. J Prof Nurs 2005;21(3):159-166.

25. Maldonado AQ, Bray BS, Woodard LJ, et al. Impact of participation on a solid organ transplant team on student pharmacists' perceptions of interprofessional roles. Am J Pharm Educ. 2013;77(4):Article 74.

26. Odegard PS, Robins L, Murphy N, et al. Interprofessional initiatives at the University of Washington. Am J Pharm Educ. 2009;73(4):Article 63.
27. Dobson RT, Stevenson K, Busch A, Scott DJ, Henry C, Wall PA. A quality improvement activity to promote interprofessional collaboration among health professions students. Am J Pharm Educ. 2009;73(4):Article 64.

28. Hagemeier NE, Hess R, Jr., Hagen KS, Sorah EL. Impact of an interprofessional communication course on nursing, medical, and pharmacy students' communication skill self-efficacy beliefs. Am J Pharm Educ. 2014; 78(10):Article 186.

29. Pedrami F, Asenso P, Devi S. Using text analytics of AJPE article titles to reveal trends in pharmacy education over the past two decades. Am J Pharm Educ. 2016;80(6):Article 104.

30. Shrader S, Griggs C. Multiple interprofessional education activities delivered longitudinally within a required clinical assessment course. Am J Pharm Educ. 2014;78(1):Article 14. 31. Shrader S, McRae L, King WMt, Kern D. A simulated interprofessional rounding experience in a clinical assessment course. Am J Pharm Educ 2011;75(4):Article 61.

32. Wilbur K, Hasnani-Samnani Z, Kelly I. Interprofessional education activity among undergraduate nursing and pharmacy students in the Middle East. Nurse Educ. 2015;40(4):163-164. 33. Jones R, Pitama S, Huria T, et al. Medical education to improve Maori health. N Z Med J. 2010;123(1316):113-122.

34. McKimm J, Sheehan D, Poole P, et al. Interprofessional learning in medical education in New Zealand. N Z Med J. 2010;123(1320):96106.

35. Jowsey T, Yu T-CW, Ganeshanantham G, et al. Ward calls not so scary for medical students after interprofessional simulation course: a mixed-methods cohort evaluation study. BMJ Simulation and Technology Enhanced Learning. 2018.

36. Parsell G, Bligh J. The development of a questionnaire to assess the readiness of health care students for interprofessional learning (RIPLS). Med Educ. 1999;33(2):95-100.

37. McKimm J, Forrest K. Essential simulation in clinical education; 2013.

38. Tweed MJ, Bagg W, Child S, Wilkinson T, Weller JM. How the trainee intern year can ease the transition from undergraduate education to postgraduate practice. N Z Med J. 2010;123(1318):8191.

39. McCrum-Gardner E. Which is the correct statistical test to use? Br J Oral Maxillofac Surg. 2008;46(1):38-41.

40. Aiello M, Terry D, Selopal N, Huynh C, Hughes E. Examining the emerging roles for pharmacists as part of the urgent, acute and emergency care workforce. The Pharm J. 2017;9(2).

41. Curley LE, Moody J, Gobarani R, et al. Is there potential for the future provision of triage services in community pharmacy? J Pharm Policy Pract. 2016;9:29.

42. Stout RJ, Cannon-Bowers JA, Salas E, Milanovich DM. Planning, shared mental models, and coordinated performance: an empirical link is established. Human Factors: J of the Human Factors and Erg Soc. 1999;41(1):61-71.

43. Pittenger AL, Westberg S, Rowan M, Schweiss S. An interprofessional diabetes experience to improve pharmacy and nursing students' competency in collaborative practice. Am J Pharm Educ. 2013;77(9):Article 197.

44. Shrader S, Kostoff M, Shin T, et al. Using communication technology to enhance interprofessional education simulations. Am J Pharm Educ. 2016;80(1):Article 13.

45. Jorgenson D, Dalton D, Farrell B, Tsuyuki RT, Dolovich L. Guidelines for pharmacists integrating into primary care teams. Can Pharm J (Ott). 2013;146(6):342-352. 


\section{American Journal of Pharmaceutical Education 2019; 83 (6) Article 6848.}

Appendix 1. Student Quotes, Organized By Theme and Subtheme

\section{Roles and Teamwork}

i. Clarity of own role and other health care professionals' roles - strengths and limitations

"Completing the sims helped me understand what I could/could not do and how I can make myself useful." [Pharmacy student 1]

"Some health professionals have gaps about drug knowledge; and I can help fill these in." [Pharmacy student 24]

"Unsure where pharmacists fit in with the hierarchy. Felt underutilised." [Pharmacy student 4]

"Didn't really hold a role in the acute care of patient. One priority, is drug causing this?" [Pharmacy student 74]

ii. Effective team work

"I learnt about the different perspectives that each profession had in regard to prioritisation. After integrating these perspectives, I developed my own skill of prioritisation further." [Pharmacy student8]

"When you are from a specific profession, your view towards what's important can be biased maybe due to limited learning related to your profession. Discussing it with other students helped to put a conclusion to this." [Pharmacy student 54]

"Learnt that Dr's don't know everything and aren't afraid to ask for help from anyone in the patient care team. Nurses contribute a lot in the management of patients and provide Drs and pharmacists a lot of info about the patient/situation." [Pharmacy student 79]

\section{Communication Development}

i. Development and practice of interprofessional communication, respectful assertion and confidence

"[I] really learnt how to communicate effectively, not just hinting and hoping but also [how to] be respectful and not aggressive." [Pharmacy student 56]

"I have learnt that voicing my thoughts aloud is a very useful strategy as most of these thoughts were valid problems that had to be addressed and I could form solutions. I just had to be confident in communicating them to other health professionals." [Pharmacy student 31]

\section{Knowledge}

i. Own and others' knowledge

"All students in each profession still had a lot more to learn about their roles as well as healthcare in general. Nurses have a lot more practical knowledge than I thought." [Pharmacy student 6]

"It helped me understand how valuable knowledge of different disciplines was to the overall health outcome of the patient."

[Pharmacy student 52]

ii. Preparedness and under-preparedness

"I felt like we should have a bigger outlook of the clinical setting. Felt way disadvantaged compared to the other med \& nursing students." [Pharmacy student 3]

"I know that pharmacists have an important role in the patient care team, however it was quite confusing at first to decide what to do. If we had more experience at hospitals this would have been much easier." [Pharmacy student 76]

iii. Knowledge sharing

"The knowledge sharing helped me learn a lot." [Pharmacy student 31]

"Discuss/group work facilitates learning." [Pharmacy student 32]

\section{Communication Strategies}

i. Tools explicit and tools described

"I learned the ISBAR communication tool - useful for handovers to other health professionals and when making phone calls."

[Pharmacy student 34]

"I learnt the importance of communication and that taking a step back and summarise on what's going on in the scenario." [Pharmacy student 44]

"PACER AND CUSS strategies practicing/simulating cases in which communication is key and vital to patient management."

[Pharmacy student 53]

\section{Broader Management Skills}

i. Logistical time management and resources

"That we need to prioritise according to how urgent the situation is, and how accessible our resources are." [Pharmacy student 6]

"The priority is not always prioritised due to medical issue, but sometimes it's prioritised according to time management e.g. walking from ward to ward." [ Pharmacy student 13]

ii. Triage, urgency and consequence of care

"Need to put the most urgent/life threatening matter on top of the priority list." [Pharmacy student 16]

"Look at/consider the consequences of each problem encountered and prioritise accordingly." [Pharmacy student 18]

iii. Patient's perspective

"I learnt that the patient is the most important, and we all need to work together to ensure the best patient care." [Pharmacy student 77] 


\section{American Journal of Pharmaceutical Education 2019; 83 (6) Article 6848.}

\section{Simulation and Practice}

i. Opportunity to practice

"Being in the simulation is a good test of being in this situation. More practice may be useful." [Pharmacy student 29]

ii. Practice demonstrates roles

"I learnt more about the clinical setting as even in hospital pharmacy placements we do not get to see much acute situations. This is a good experience to see what usually happens when patients are being assessed by nurses/doctor. I learnt the need to be systematic." [Pharmacy student 42]

iii. Being systematic and procedure examples

"Assessment needs to be systematic to make sure everything is covered." [Pharmacy student 77] 
American Journal of Pharmaceutical Education 2019; 83 (6) Article 6848.

Appendix 2. A Summary of the IPL in a Simulated Patient Care Environment (WardSim) in 2014

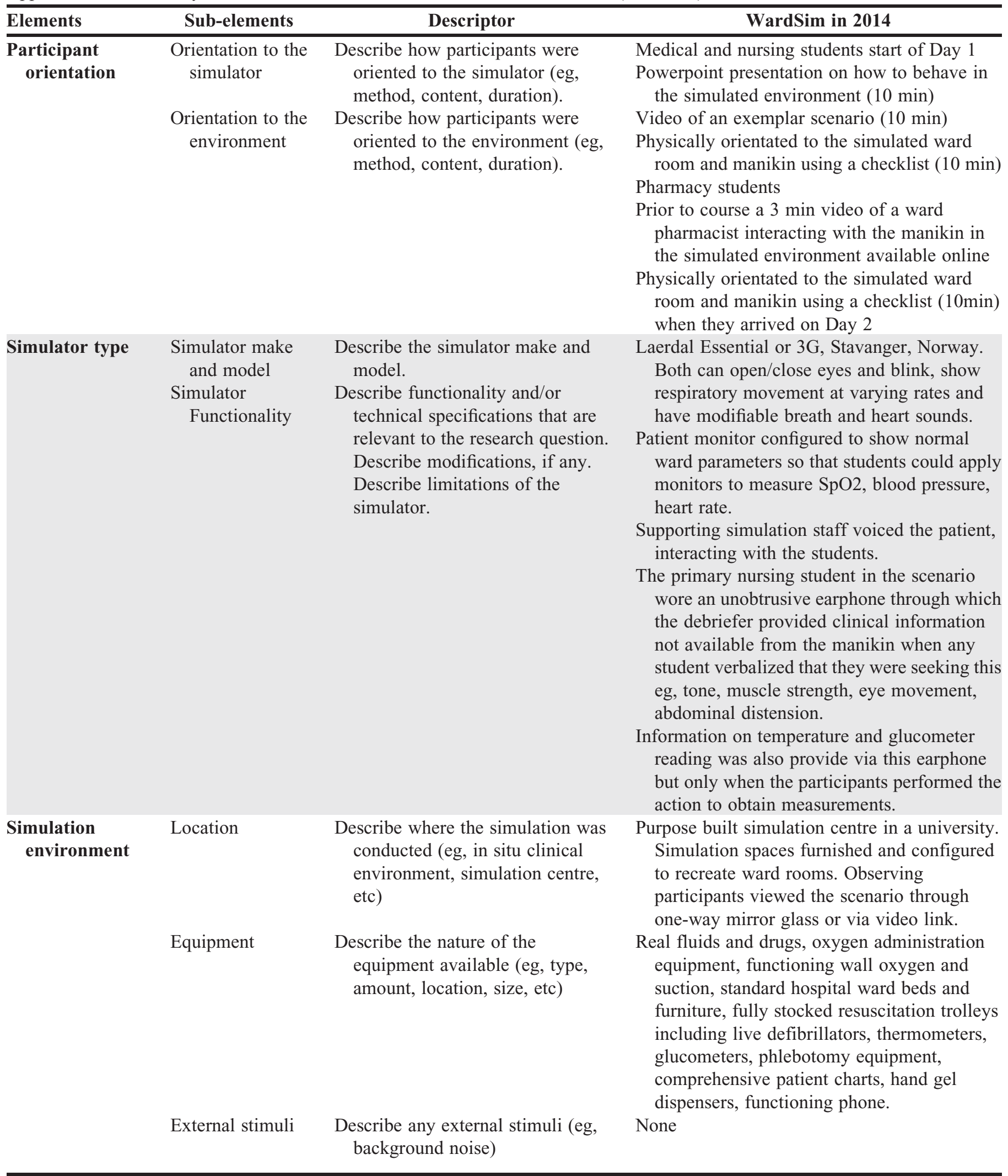




\section{American Journal of Pharmaceutical Education 2019; 83 (6) Article 6848.}

Appendix 2. (Continued)

\begin{tabular}{|c|c|c|}
\hline Elements & Sub-elements & Descriptor \\
\hline \multirow[t]{3}{*}{$\begin{array}{l}\text { Simulation } \\
\text { event/scenario }\end{array}$} & Event description & $\begin{array}{l}\text { Describe if the event was } \\
\text { programmed and/or scripted (e } \\
\text { orientation to event, scenario } \\
\text { progression, triggers). If a } \\
\text { scenario was used, the scenaric } \\
\text { script should be provided as an } \\
\text { appendix. }\end{array}$ \\
\hline & $\begin{array}{l}\text { Learning } \\
\text { objectives }\end{array}$ & $\begin{array}{l}\text { List the learning objectives and } \\
\text { describe how they were } \\
\text { incorporated into the event. }\end{array}$ \\
\hline & $\begin{array}{l}\text { Group vs } \\
\text { individual } \\
\text { Practice }\end{array}$ & $\begin{array}{l}\text { Describe if the simulation was } \\
\text { conducted in groups or as } \\
\text { individuals. }\end{array}$ \\
\hline
\end{tabular}

Use of adjuncts

Facilitator/

operator

characteristics
Describe if adjuncts (eg, moulage, media, props) were used.

Describe experience (eg, clinical, educational), training (eg, fellowship, courses) and profession.
Pilot testing
Actors/
confederates/
standardised/
simulated
patients

Describe if pilot testing was conducted (eg, number, duration, frequency).

Describe experience (eg, clinical, educational), training (eg, fellowship, courses), profession and gender. Describe various roles, including training, scripting, orientation, and compliance with roles.
WardSim in 2014

Scenarios had detailed run sheets, were programmed and scripted for patient responses and responses to phone calls, and for progression through the scenario. Experienced simulation technicians controlled the manikin and voiced the patient with guidance from clinical faculty for unexpected participant actions.

Each scenario had 1-2 specific knowledge or skills objectives, as well as common course objectives (see main paper).

Mixed professional groups of 8-11 learners rotated through 8 scenarios. Pharmacy students joined the course on Day 2.

Day 1: 1-2 nursing students and 1 medical student assessed and managed the situations, others observed, all took part in the debrief.

Day 2: pharmacy students observed the first scenario and were present in the debrief, in the subsequent 3 scenarios a pharmacy student joined the other students to assess and manage the situation, all took part on the debrief.

All patients had patient identification bracelets, appropriate wigs and clothing, functioning intravenous catheter, and other moulage as appropriate eg abdominal wound dressing and drains, urinary catheter.

Participants could record a 12 lead ECG using realistic props.

Faculty members were drawn from the medical, nursing and pharmacy programs. Each member had an interest in education and prior to WardSim undertook a half-day formal training session in scenario-based learning including debriefing. Faculty seniority ranged from medical interns 3 years ahead of the medical students in training, to very experienced senior clinicians. The typical ratio of faculty to students was 1:5 and of simulation technical staff to students, 1: 20.

A pilot course was conducted in Nov 2013 with volunteer students from the 3 disciplines.

N/A 


\section{American Journal of Pharmaceutical Education 2019; 83 (6) Article 6848.}

Appendix 2. (Continued)

\begin{tabular}{llrl}
\hline Elements & Sub-elements & Descriptor & WardSim in 2014 \\
\hline $\begin{array}{l}\text { Instructional } \\
\text { design (for } \\
\text { educational } \\
\text { interventions) }\end{array}$ & Duration & $\begin{array}{c}\text { Describe the duration of the } \\
\text { educational intervention. If the } \\
\text { intervention involves more than } \\
\text { one segment, describe the } \\
\text { duration of each segment. }\end{array}$ & $\begin{array}{c}\text { Scenarios: Student nurse briefing (handover) } 5 \\
\text { min then } 10 \text { min to assess, call for assistance } \\
\text { and manage the situation. Medical student } \\
\text { then joined for 15 min. Debrief duration as } \\
\text { above, 20-30 min. Pharmacy students } \\
\end{array}$ \\
& & $\begin{array}{l}\text { accompanied the nursing students in } \\
\text { scenarios 6-7, and in scenario } 8 \text { attended the } \\
\text { patient before the nursing student. }\end{array}$ \\
& & Describe the timing of the & Data collection at end of course
\end{tabular}

educational intervention relative

to the time when assessment/data

collection occurs (eg,

just-in-time training).

Frequency/ repetitions

Clinical variation

Standards/ assessment

Adaptability of intervention

Range of difficulty

Non-simulation Interventions and adjuncts
Describe how many repetitions were permitted and/or the frequency of training (eg, deliberate practice).

Describe the variation in clinical context (eg, multiple different patient scenarios).

Describe predefined standards for participant performance (eg, mastery learning) and how these standards were established.

\section{Describe how the training was responsive to individual learner needs (eg, individualised learning).}

Describe the variation in difficulty or complexity of the task.

Describe all other non-simulation interventions (eg, lecture, small group discussion) or educational adjuncts (eg, educational video), how they were used, and when they were used relative to the simulation intervention.
Data collection at end of course

No repetition of individual scenarios

8 scenarios: fall, chest pain, shortness of breath, hypoglycaemia, postoperative abdominal pain and shortness of breath, minor bleeding in anticoagulated patient, and new neurological symptoms where medication interaction or an iatrogenic overdose were potential causes.

No formal assessment.

Expected actions for each profession were available for debriefer reference. These were created in consultation with educators and clinicians from each profession and appropriate for the training level at which the participants were asked to perform.

The scenario flow was scripted to respond to the actions of the learners. If required for progression a debriefer would enter the room in role as a senior staff member and guide the students as would occur clinically.

Debriefing was responsive to student needs.

All scenarios were of similar difficulty.

Scenarios/debriefs were intercalated in larger groups with 8 classroom activities as follows: Accurate and structured documentation of clinical notes A structured clinical communication tool: ISBAR (Introduction, Situation, Background, Assessment, Request/ Recommendation) Interprofessional patient handover Patient early warning scoring tools Clinical task prioritization* Graded assertiveness $=$ speaking up* Medication reconciliation* Identification of medication charting errors** pharmacy students present and participated in these, after 
American Journal of Pharmaceutical Education 2019; 83 (6) Article 6848.

Appendix 2. (Continued)

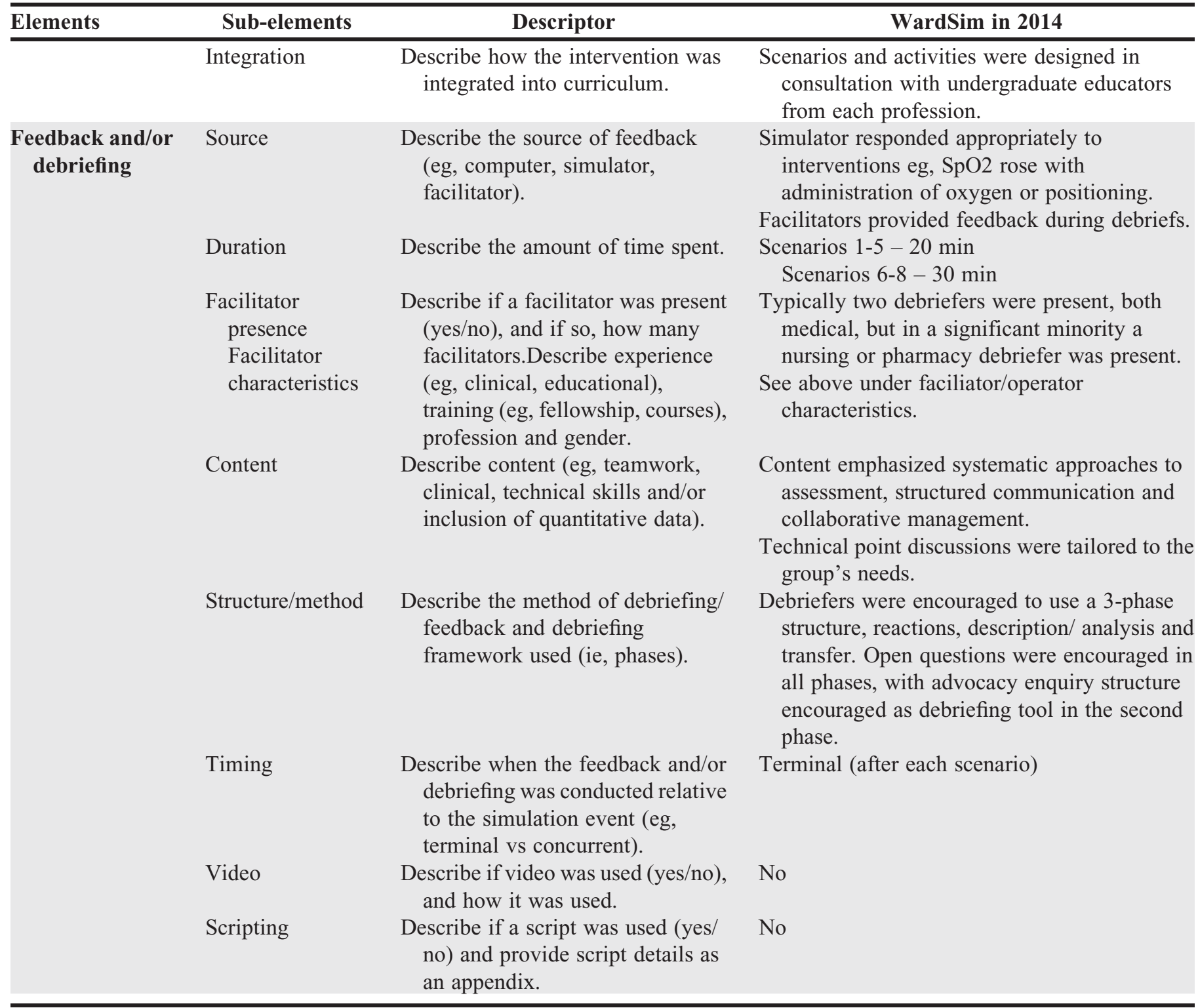

